\title{
Erratum
}

\author{
Research Article
}

\section{Economic valuation of policies for managing acidity in remote mountain lakes: Examining validity through scope sensitivity testing}

Ian J. Bateman, Phillip Cooper, Stavros Georgiou, Ståle Navrud, Gregory L. Poe, Richard C. Ready, Pere Riera, Mandy Ryan and Christian A. Vossler

Please note that the following two amendments concern the above mentioned article that appeared electronically Online First on June13, 2005 (this issue, pp. 274-291).

1. - the first name of the author Cooper is Philip (and not Phillip).

2. - the correct grant reference number is EVK1-CT-1999-00032 (instead of: EVK1-CT-2002-00121). 